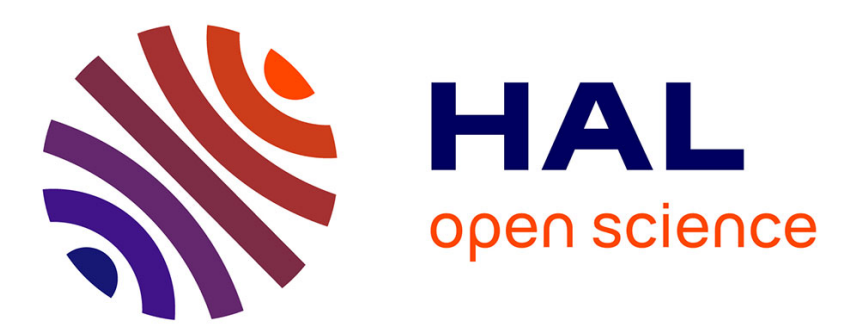

\title{
The social construction of safety: Comparing three realities
}

\author{
Hortense Blazsin, Franck W. Guldenmund
}

\section{To cite this version:}

Hortense Blazsin, Franck W. Guldenmund. The social construction of safety: Comparing three realities. Safety Science, 2015, Editors' corner 2013, 71, pp.16-27. 10.1016/j.ssci.2014.06.001 . hal01022500

\section{HAL Id: hal-01022500 \\ https: / hal-mines-paristech.archives-ouvertes.fr/hal-01022500}

Submitted on 25 Nov 2014

HAL is a multi-disciplinary open access archive for the deposit and dissemination of scientific research documents, whether they are published or not. The documents may come from teaching and research institutions in France or abroad, or from public or private research centers.
L'archive ouverte pluridisciplinaire HAL, est destinée au dépôt et à la diffusion de documents scientifiques de niveau recherche, publiés ou non, émanant des établissements d'enseignement et de recherche français ou étrangers, des laboratoires publics ou privés. 


\section{The Social Construction of Safety: Comparing Three Realities}

hortense Blazsin, Mines Paristech, France \& Frank Guldenmund, Delft University of Technology, NETHERLANDS

\section{Keywords}

Safety culture; culture development; social constructivism; discourse analysis; sensemaking.

\section{Abstract}

This study focuses on the (development of) safety culture of a big gas distribution company. Using a social constructionist framework, we explore the discourses constructed by three of the organization's subgroups in relation to safety. Those groups, which are all situated at field level from a single working site, and therefore share a similar proximity to safety issues, occupy different hierarchical and functional positions. We assumed that each group may be considered as a specific social world, within which a specific perception of, and relationship with, safety is constructed, and that discourse analysis offers access to this construction. Individual semi-structured interviews were carried out to gather the discourses and analysed in an ethno-methodological and conversation analysis perspective. Our discourse analysis allowed us to confirm our assumption by identifying that from one shared 'root' perception, three different constructions of safety stem. They appear to depend on both the group's specific jobs, and group positioning within the organization. Building on Berger and Luckmann's development cycle and on Weick's theory of sensemaking, we interpret those results as ensuing from a hiatus in the organization's rules enactment process and culture development cycle.

\section{Introduction}

The study presented in this article stems from the willingness of a major French gas distribution company to obtain a better understanding of its safety culture. This understanding might also help resolve a contradiction that seems to permeate various safety practices. It appears that despite explicit engagement and a significant investment in safety by top-management, also recognized as such at all levels of the organization, a certain aloofness can be observed at local levels, with appropriation of the safety policy in some cases still pending. This study therefore also aims at uncovering the reasons for this gap, examining separately recognition of the company's safety policy and its appropriation by its members. Our purpose is therefore not to evaluate the 'objective' safety performance of the organization, i.e. the ability to manage safety, prevent accidents, etc., which would require an altogether different approach and research design. From a traditional social science perspective, our aim is to understand what the perceptions pertaining to safety are, the factors that contribute to determining these perceptions, and how, ultimately, these individual and group perceptions are constructed as larger discourses and, possibly also, cultures.

Building on the empirical assessment of a contradiction identifiable within the organization's safety culture, we formulated a research question: Do field-level world(s) and associated local culture(s) lead employees to recognize but not appropriate the organization's safety policy and if so, why? Using a social constructionist perspective, we designed a study to analyse how field level employees make sense of safety. Instead of focusing on the obvious top vs. down, or headquarters vs. field level opposition, we selected three subgroups from one single working site, which are all situated at field level, but occupy different hierarchical and functional positions. Firstly, we outline the organizational context within which the study took place. Thereupon, we will present the reasons why we chose the social constructionist perspective to look at the three groups' sensemaking. We will then 
introduce our research question and hypothesis, and the study we've designed to address it before proceeding with presenting our results and discussing them, after what we will conclude and open some perspectives for further research.

\section{Organizational context: a paradoxical perception of organizational safety engagement}

The company at the heart of our study is responsible for the delivery of natural gas from the transport network to the end-user, i.e. households or companies. This involves monitoring the status of the network and carrying out any maintenance operations that are necessary to avoid leaks; connecting new customers; disconnecting parts of the network; modernising the network; managing leaks/emergencies; and finally, coordinating with other companies whose activities may have an impact on gas installations, which includes pipelines and associated equipment, regulating devices, individual or collective connections, storage cabinets, etc.

Although its gas distribution activity has existed since the half of the $20^{\text {th }}$ century, the corporation as it exists today is only six years old. It was created as a result of a 1998 European legislation which made it compulsory for energy distributors to become full entities, separate from energy producers and vendors. As an organization it is therefore at once old and quite new, a blend of historic professional expertise and a more recently founded organizational identity, impacting its organizational and safety culture. Its birth as a legal entity was surrounded by three important gasrelated accidents, which happened within weeks of each other. Not only did these events transform the industry's regulatory environment, they subsequently decided to put safety as the company's first priority and restructure its safety policy around this new primacy. If safety had always been part of the job, it then became the job itself. In short, the company's safety policy and organizational culture from which it is derived are hardly six years old, and it is nevertheless developing from the foundations of a previous professional culture.

In the past six years, considerable financial and human means have been invested in order to develop tools and methods which could help implement the desired safety culture where safety takes precedence over any other aspect of an activity. Among other things, those investments have led to activities such as a Structured Post-incident and Post-accident Feedback Process and a Human \& Organizational Factors Process (Desmorat, 2013), that aim to favour transparent upward feedback on 'real' work practices and enhance organizational learning. It was in this context that two years ago, the research project from which the present article stems was initiated.

\section{A social constructionist perspective on (safety) culture}

\section{Conceptual framework}

Considered from a theoretical perspective, the empirical question pertaining to the organization's safety culture and underlying contradiction points to a number of issues with regards to safety culture and more broadly, to organizational culture, of which safety culture is an aspect (see Guldenmund, 2010). Following Schein, organizational culture may be considered as 'a dynamic phenomenon that surrounds us at all times, being constantly enacted and created by our interactions with others and shaped by leadership behaviour, and a set of structures, routines, rules, and norms that guide and constrain behaviour' (Schein, 2004, p.1). Our aim is therefore to develop a better understanding of the 'dynamic phenomenon' specific to the organization we are focusing on. In line with many current theories of organizational culture, we particularly take the differentiated viewpoint, which states that organizations divide into subgroups along such lines as geography, 
departments, hierarchical levels, etc. (Martin, 2002). This is consistent with what Gergen, a prominent representative of the social constructionist paradigm, writes about what he calls 'The ethical challenge of global organization'. According to Gergen, "As the organization expands, a strong tendency toward specialization occurs. Most importantly, what is obvious, rational and valuable in one part of the organization is seldom duplicated in others. In effect, a multiplication of realities is generated, reducing the intelligibility and the rhetorical efficacy of the singular 'voice from the top" (Gergen, 2001, p.142). An equivalent proposition of this statement, considered from the perspective of the individuals, can be found in Weick's work (Weick, 2010, p.10), and states that social relations such as power are the only way to stabilize the shared meaning of reality.

Gergen's and Weick's analyses of multiple realities coexisting within one organization seems to reflect the empirical assessment of a gap separating the perception from the appropriation of the company's safety policy by field level people. This gap suggests that the 'safety reality' experienced at field level differs from the one experienced at headquarters level. ${ }^{1}$ The current study is therefore fully embedded within the social constructionist paradigm, which will be defined as follows: 'Social constructionism denies that our knowledge is a direct perception of reality. In fact it might be said that as a culture or society we construct our own versions of reality between us. [...] All knowledge is derived from looking at the world from such perspective or other, and is in the service of some interests rather than others' (Burr, 2003, p.6). Considering the world as being a pure social construction denies it an objective reality, the essence of which would be directly (and neutrally) accessible to people, who may only access it through the mediation of artefacts that they, individually and as a group, have constructed. As such, social constructionism aims to expose the specific political, social, historical etc. conditions which orient and construct a specific perception of reality and which sediment into symbolic and material artefacts. Organizational culture being precisely a blend of symbolic and material artefacts (for instance, see Hofstede, 2010), social constructionism appears as particularly adequate to analyze culture under any of its forms - in our case, safety culture.

In particular, the social constructionist paradigm seems useful to explore the gap empirically observed in the organization's safety culture: does it stem from a willingness from field-level people to distance themselves from headquarters and from a felt top-down imposition of knowledge and rules, a phenomenon already broadly documented by research in safety science and sociology (see for instance Terssac, 2003). Or, consistent with the social constructionist perspective, may this gap be attributed to a deeper phenomenon, namely the coexistence of subgroups, which have developed separately their own specific culture, and subsequently their specific perception of and relationship with safety? In other words, may this gap between recognition and appropriation of the organization's safety policy result from the coexistence of local 'realities' alternate (and possibly unrelated) to that proposed by the organization's headquarters? As organizations are composed of individuals who experience and subsequently construct their sense of reality, considering the microlevel of individual sensemaking appears as a necessary first step to question the macro-level of sensemaking at the heart of organizational culture. In this perspective, we will be using Weick's work to address the micro level, before turning to Berger \& Luckmann to reflect on the macro level.

\footnotetext{
${ }^{1} \mathrm{HQ}$ level designates the national corporate $\mathrm{HQ}$; it should be mentioned that there are also regional HQs which relay information between national $\mathrm{HQ}$ and field level).
} 
Weick's theory of sensemaking to analyze how safety and safety policy are enacted locally

By saying that 'What sensemaking does is address how the text that is constructed as well as how it is read. Sensemaking is about authoring as well as reading' (Weick, 1995, p.7), Weick asserts the role played by the individual in the construction of the environment (s)he experiences and the context (s)he evolves in. It is due to this 'presupposed pattern' that people are able to literally make sense of situations and subsequently act, hence confirming and strengthening the pattern. This retroactive process of sensemaking > action > pattern confirmation is termed 'enacting', which states that action is an integral part of the reality construction process (see for instance Weick, 1995, p.30). The enactment phase of sensemaking appears as especially important in a safety culture perspective, as it is the moment when safety culture materializes into a safe/unsafe action, and is confirmed/denied as a culture, i.e. a set of beliefs, values, basic assumptions, etc. by said action. As such, action will play an important part in our research design.

\section{Berger \& Luckmann's model of culture development applied to the organization} In addition to Weick's theory of sensemaking, we will be using an adjusted version of Berger and Luckmann's model of culture development (Figure 1) (see also Guldenmund, 2014, for a similar adaptation) to help interpret the organizational aspects of our results. The representation of culture development as a continuous cycle seems particularly useful for our perspective, as sensemaking and simultaneous construction of reality appear as ongoing, dynamic, never-ending processes. Indeed according to Follet (quoted in Weick, 1995, p.32), 'there is no result of process but only a moment in process'.

Figure 1 -Adapted representation of Berger and Luckmann's model of culture development

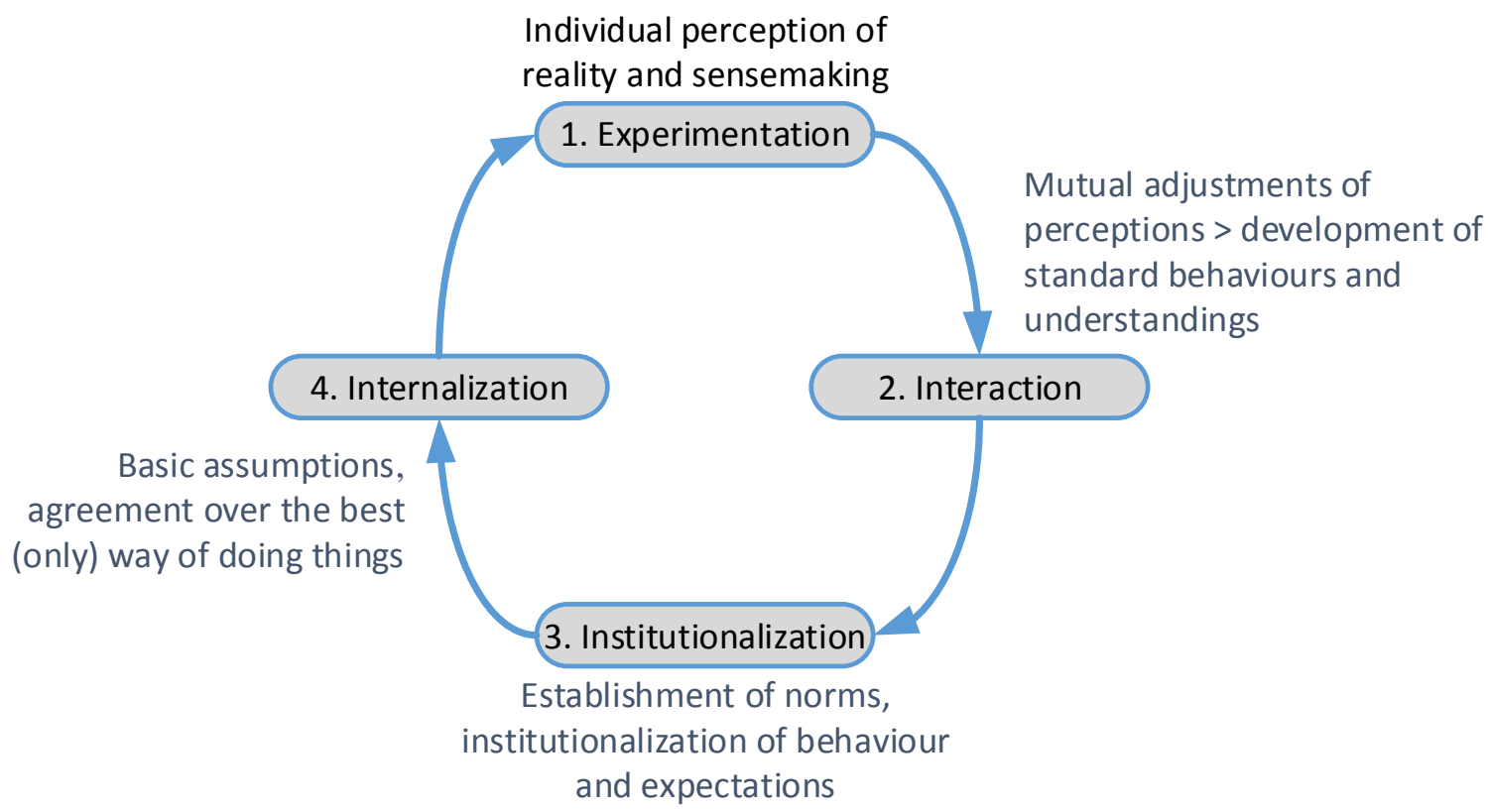

In the first box, 'Experimentation', a member of a group experiences a specific situation, of which he develops his own perceptions and makes specific sense. With regard to risk and safety, these individual perceptions will partly determine the sensemaker's behaviour, e.g. what is risky and safe behaviour. The result of this process is an individual's understanding of reality. Or, to use Berger and Luckmann's words, the stage of 'reality [...] interpreted by men and subjectively meaningful to them as a coherent world' (1966, p.33). Box number two corresponds to the 'Interaction' stage, which may be defined as 'objectivations of subjective processes (and meanings) by which the 
intersubjective common-sense world is constructed' (ibid). This is the stage where members of a group interact through formal and informal discussions, giving rise to mutual adjustments, agreements and expectations with regard to each other's behaviours. This stage ultimately results in shared understandings, such as standards of behaviour, roles and norms. The third box, 'Institutionalization', introduces the formal processing of standards and norms, i.e. the establishment of norms and the institutionalization of behaviour and expectations. At this stage a specific set of representations and actions becomes explicit and official, and may be formalised so that, amongst other things, they can be taught to newcomers. This stage may be considered as one of 'organizational consciousness', i.e. 'the reality of everyday life appears already objectified, that is, constituted by an order of objects that have been designated as objects before my appearance on the scene' (Berger and Luckmann, 1966, p.35). Finally, the fourth box, titled 'Internalization', pictures the situation in which norms, standards and expectations are accepted to the extent that they are considered the 'best' or, perhaps, the 'only' way of doing things. Members of the group share a comparable understanding of reality, at least with regard to the part of reality the group acts on. This understanding is internalised by the members of the group and patterns into 'basic assumptions' with which individuals within the group understand reality, which in turn influences their perception of reality and subsequently, the way they make sense of the situation they experience.

This model implies a number of considerations regarding the nature of culture that are relevant to our study. Firstly, as it has to go through a number of stages where each stage takes time in its own right, the development process of an organizational culture takes time to complete. It is constantly ongoing, as all new experiences may be added to the process of mutual adjustment and impact the other stages. Another aspect which results from this iterative process and appears as characteristic of both organizational and safety culture, is its articulation of both cognitive/symbolic and practical/behavioural aspects. Quoting Hopkins (2006), "perhaps the best known definition of organizational culture, 'the way we do things around here' (Deal and Kenney, 1982) [...] carries with it the connotation that this is the right, or appropriate or accepted way to do things. These judgements stem necessarily from shared assumptions or values."

Secondly, the process depends on the composition of the group, its internal dynamics, the particular context in which the group operates, and so on. As such, the outcome is more arbitrary than intentional. It may still be influenced, either by internal members and/or by external people. For instance, regarding the safety culture of a specific organization, corporate headquarters may try to influence local cultures through such means as organizational design, recruitment of new group members, intended implementation of norms, and so on. Yet, considering the importance of the factors developed by the group, the outcome of such measures is difficult or even impossible to predict. Such measures may also include the implementation of standards that do not result from a consensus between group members, who, because of that, do not recognize them as their standards, and are therefore not internalized as 'basic assumptions' but rather as 'obligations', i.e. 'the way we have to do things around here' instead of 'the way we do things around here'. We broadly define organizational culture as "a fuzzy set of attitudes, beliefs, behavioural conventions, and basic assumptions and values that are shared by a group of people, and that influence each member's behaviour and each member's interpretations of the 'meaning' of other people's behaviour" (Spencer-Oatey, 2000). We will pick up this model again later on as it will help us in interpreting our results. 


\section{Research question \& methodology}

\section{Research question and justification}

Those initial elements led to formulating our research question asking whether the field-level world(s) and associated local culture(s) lead employees to recognize but not appropriate the organization's safety policy. This research question raises a number of underlying topics, such as what world(s) its employees have created for themselves and the meaning of safety therein; whether employees share part, all, or none of this world, and whether this sharing of world view depends on the group they belong to. Also, how do these representations make sense and how are they enacted (cf. Weick, 1995) in daily work, where they are created through interaction?

Since 'it is the structures of our socially shared languages that are seen as producing phenomena at both the social and personal levels' (Burr, 2003, p.18), it seemed fair to gather and analyze such 'texts' and underlying 'discourses', to address our research question. Discourses may be defined as 'socially shared languages, outcrops of representations of events upon the terrain of social life' (Burr, 2003, p.44), which meaning mostly depends on the context and which constitute a 'frame of reference, 'a conceptual backcloth against which our utterances can be interpreted' (ibid.). If there is no objective reality but only local realities which are socially constructed, then it seems fair to state that there is no objective and unique frame of reference, and that within an organization, each subgroup, as a specific social world, develops its own discourse. By exposing the social conditions of their creation, deconstructing local discourses therefore offers the possibility to identify similar elements in different subgroups. The element thus identified may or may not contain traces of organizational culture, which in turn allows us to evaluate the degree of distance or proximity between the subgroups and with the organization.

Therefore, we designed our study around the gathering and analysis of three different discourses from three local groups. We considered that three was an appropriate number to ensure that data would offer some diversity, all the while remaining manageable. Indeed discourse analysis involves a serious amount of work to appropriate the data and carry out an in-depth analysis.

In this perspective, our discourse analysis will first aim at confirming whether our three subgroups have indeed constructed local safety discourses and if so, to outline the local conditions which influenced this construction. To put it differently, our aim is to analyze how safety is made sense of within each local subgroup, whether this meaning is identical from one subgroup to the other and if not, the reasons for such variation. By doing so, we will 'deal not only with the empirical variety of 'knowledge' [...], but also with the processes by which any body [sic, emphasis in the original] of 'knowledge' comes to be socially established as 'reality" (Berger and Luckmann, 1966, p.15). Ultimately, our aim is to develop a better understanding of the processes by which an organizational safety culture develops and establishes itself, on the basis of 'knowledge' which is constructed by and translated into discourses.

\section{Research design and methodology}

To gather local texts we carried out individual semi-structured interviews, primarily as a way to enquire 'openly about situational meanings or motives for action, or collecting everyday theories and self-interpretations in a differentiated and open way' (Hopf, 2004, p.203). These interviews were carried out with employees working within the organization's core activity, i.e. gas distribution, as opposed to peripheral activities such as research, design, development, and so on. 
As the interviews were conducted at a single location where prior non-participant observation had been carried out, confidence was quickly established. Each interview lasted between 60 and 90 minutes, during which a variety of work and safety-related topics were covered (see Appendix 1 for interview guide). Yet in order to reach a balance between in-depth analysis and a manageable amount of data, we decided to limit ourselves to the analysis of two questions namely, 'What is it, according to you, that makes a good gasman?', and 'What, according to you, is the company's safety policy?'. By having people tell about the positive traits they associate with their activity and professionalism, the importance of safety within this activity, and their representation of the effort the organization makes to promote safety and therefore themselves, we were aiming to identify any existing differences between the way people perceive their relationship with the organization, and how this perception reflects on their representations of safety and, ultimately, contribute to the organization's safety culture and safety performance.

\section{Focus: field level}

Subgroups were selected at field level because they are the ones primarily concerned with safety issues, being directly confronted with field work where these issues arise. As such they are literally the primary addressees of the organization's safety policy, the ones who are expected to confront the policy with actual safety issues. Moreover, their sense of safety may materialise into very real consequences in the field. Managing safety according to organizational views requires that they follow a number of principles, ranging from individual equipment to rules and procedures. Field level was also chosen because it is where distance has been most explicitly expressed during the initial phase of research. Focusing on field level therefore appeared as the first option, as it seemed to be the level where safety as a practice and safety as a policy would collide in the most frontal way, making any difference more noticeable.

\section{Sample}

Three subgroups were thereupon selected: field workers from the operations department, frontline supervisors from the operations department and network supervisors from the network operations department. The idea behind this particular selection was to include both activity-related facets and hierarchy-related facets, and have people tell about similar work experiences from their specific, local point of view.

As mentioned, field workers, who we also call 'gasmen', are the ones who carry out the actual work in the field, i.e. construction work, acts of maintenance, leak management, and so on. From a categorical perspective they are dedicated to executing acts conceived and prepared by their supervisors.

In the organization's chart, we find two sorts of jobs amongst the frontline supervisors, one that is dedicated to managing the team of field workers (human resources aspects) and the other, to preparing the work for them (technical and administrative aspects). We have grouped them into one category because of their hierarchical position and because they both play a role in safety and risk management. Their relationship to safety therefore exists through the field workers, for whom they are supposed to manage risk proactively, as they prepare work (risk analysis included) and take care of their equipment, with whom they share the rules and procedures.

Finally, network supervisors are the people in charge of operating the network, which means ensuring that gas actually flows through the pipes and goes to clients, under such conditions that 'the safety of people and goods is preserved'. They are therefore in charge of all technical networkrelated decisions and make sure that the decisions made are the safest and soundest in the long run. Although throughout the organization they may have different backgrounds, as far as our 
interviewees are concerned they are all former gasmen and frontline supervisors; therefore people with a long experience of fieldwork and field realities. Like frontline supervisors, their relationship to safety is indirect, as they work mostly from their office and rarely go into the field. Yet they are accountable (including legally accountable) for what happens to the network and are also the official managers of field workers when they are dealing with an emergency situation, e.g. a gas leak, unexplained smell of gas, and so on.

While field workers carry out their work in the field, both groups of managers are most of the time stationed at the office and manage safety issues from their office as they arise. Field workers work with both frontline supervisors and network supervisors. As they belong to different departments and fulfil different functions (basically, hierarchical vs. expertise-based management), frontline supervisors and network supervisors have opportunity to interact.

\section{Composition of subgroups}

Twenty people have been interviewed: ten field workers, five frontline supervisors from the operations department and five network managers from the network operations department. Field workers outnumber the other two groups in our sample as they do in real-life.

Interviewees of the field workers subgroup were chosen so as to mix age and background, with years of service in gas distribution ranging from one year to more than ten years; people who had prior work experience in completely different jobs (e.g. production work, firefighting, plumbing, etc.) and people whose entire career had been within the company; people who had worked on this site exclusively and people who had worked elsewhere for the company. By mixing age groups and background we therefore attempted to access an intermediary discourse which would reveal local elements while still reflecting some of the organizational elements.

Regarding the other two subgroups, as they gather a smaller number of employees in real life, it was decided to interview them all in order to maintain some numerical balance between the subgroups and to obtain as much diversity as possible within each sample. The group of frontline supervisors is composed of both 'older' employees who have occupied other positions in the company and have carried out field work, and more 'new' employees who have never been in the field as field workers. One of them has a working history in the company but the rest of the group has spent their whole working life employed in gas distribution Two out of five frontline supervisors have a working history of five to ten years, while the other three have thirty-something years of working experience. As to the network supervisors they are the more 'older' employees, whose working experience ranges from ten to thirty years, and who have always worked for the company and have started as field workers but have also occupied other functions, including frontline supervisors.

\section{Approach: discourse analysis}

Once transcribed the interviews were analysed and classified according to a discourse analysis perspective, following the ethno-methodological and conversation analysis tradition (Wetherell, 1998). As reality has no essence per se and can only be constructed socially, the aim of discourse analysis is not to find some hidden truth behind the words of interviewees, but to 'work with what has actually been said or written, exploring patterns in and across the statements and identifying the social consequences of different discursive representations of reality' (Jorgensen, Philips, 2002, p.21).

Our aim was to identify the representations associated with safety and risk and how each group makes sense of or constructs safety and safety-related issues. The actual technique that we used was inspired by the qualitative analysis methodology advocated by Paille and Mucchielli (2005) and 
was carried out both manually and using a content analysis software, Dedoose (www.dedoose.com). We systematically and repeatedly read each interview in order to identify and delimit the notions and representations evoked as they emerged. Each theme identified was then summarized and listed in a chart. Once this work was completed we worked within each category of workers and grouped the topics into broader thematic categories which we then analysed with relations to one another (patterning), in order to explain how each group makes sense of safety and constructs its related discourse. We finally made a comparison between the groups, so as to understand whether the safety discourses differed from group to group, and tried to account for any difference by relating each discourse to one another, to the specific work carried out by each group, to the position occupied by each group within the organization and to the broader organizational context.

\section{Main results}

This section will present the main results which emerged from the discourse analysis of each category of workers. We will start by giving a general overview of our findings, before reviewing those findings that relate to the relationship with safety and with the organization's safety policy, construction of gasmen professionalism and the safety part therein and finally the way time is experienced, illustrating a specific experience of safety issues.

\section{Overview of results}

Distance (functional, geographical, and hierarchical) was quickly confirmed as a recurring theme in the interviews. According to Berger and Luckmann (1966, p.36), 'The reality of everyday life is organized around the 'here' of my body and the 'now' of my present. [...] The reality of everyday life is not, however, exhausted by these immediate presences, but embraces phenomena that are not present 'here and now'. This means that I experience everyday life in terms of differing degrees of closeness and remoteness, both spatially and temporally. Closest to me is the zone of everyday life that is directly accessible to my bodily manipulation. [...] In this way it is my world par excellence [emphasis in the original]. I know, of course, that the reality of everyday life contains zones that are not accessible to me in this manner. But either I have no pragmatic interest in these zones or my interest is indirect in so far as they may be, potentially, manipulative zones for me.' The distance expressed by all three groups towards the organization's safety policy seems consistent with what Berger and Luckmann say about distant worlds - in this case, the organization's distant corporate world. 'Distance', although symbolic, is to be taken literally, i.e. a number of hierarchical steps separate field level from headquarters (five steps separate supervisors from $\mathrm{HQ}$, which makes it six from gasmen to $\mathrm{HQ}$ ); this implies that despite existing methods to ensure there is both bottom-up and top-down information circulation, the functional and hierarchical realities which are experienced are so estranging that this gap may be difficult to bridge. Such distance underlies the already well-documented perception amongst field workers that knowledge about work and 'true' safety lies with field employees rather than with corporate managers (Terssac, 2003). We considered this not as a result, but as an aspect which had to be pinpointed in order to move forward with our research.

What we do consider as a result is the fact that behind a similar expression of distance towards the organization's safety policy, different perceptions of and relationship with actual safety emerge. Such differences seem to imply specific relationships with the organization itself, and to be influenced by the nature of each group's activity, and its positioning within the organization. These are summed up in Table 1. 
Table 1 - Summary of results of discourse analysis

\begin{tabular}{|l|l|l|l|}
\hline & \multicolumn{1}{|c|}{$\begin{array}{c}\text { Field } \\
\text { workers }\end{array}$} & \multicolumn{1}{c|}{$\begin{array}{c}\text { Frontline } \\
\text { supervisors }\end{array}$} & \multicolumn{1}{c|}{$\begin{array}{c}\text { Network } \\
\text { supervisors }\end{array}$} \\
\hline $\begin{array}{l}\text { Perception } \\
\text { of rules }\end{array}$ & $\begin{array}{l}\text { Ill-adapted to field } \\
\text { realities, mostly } \\
\text { 'umbrellas' }\end{array}$ & $\begin{array}{l}\text { Fuzzy and ill-adapted, } \\
\text { to be complied with as } \\
\text { much as possible }\end{array}$ & $\begin{array}{l}\text { Potentially useful, but } \\
\text { second to all- } \\
\text { important aim to } \\
\text { preserve workers' } \\
\text { safety }\end{array}$ \\
\hline $\begin{array}{l}\text { Perception } \\
\text { of risks }\end{array}$ & $\begin{array}{l}\text { Primarily gas-related risks; } \\
\text { occupational accidents, } \\
\text { traffic-related risks }\end{array}$ & $\begin{array}{l}\text { Occupational risks, } \\
\text { traffic-related risks }\end{array}$ & Gas-related risks \\
\hline $\begin{array}{l}\text { Perception } \\
\text { of safety policy }\end{array}$ & $\begin{array}{l}\text { 'Propaganda' (i.e. } \\
\text { 'insincere'), 'safety } \\
\text { umbrella' }\end{array}$ & $\begin{array}{l}\text { All-ambitious aims, } \\
\text { disconnected from } \\
\text { field reality }\end{array}$ & $\begin{array}{l}\text { Quantified safety } \\
\text { policy, useless }\end{array}$ \\
\hline $\begin{array}{l}\text { Perception } \\
\text { of a 'good gasman' }\end{array}$ & $\begin{array}{l}\text { Ability to appropriate the } \\
\text { frame and fit it, if } \\
\text { necessary, to actual } \\
\text { situations } \\
\text { ('technical command, } \\
\text { 'professionalism', 'self- } \\
\text { confidence', 'persistence', } \\
\text { 'solution-oriented', 'ability } \\
\text { autonomously and } \\
\text { within the anticipated, } \\
\text { rules-based frame } \\
\text { situation', etc. ) }\end{array}$ & $\begin{array}{l}\text { ('ability get the job } \\
\text { properly done', } \\
\text { 'autonomy', } \\
\text { 'knowledge of gas and } \\
\text { associated techniques', } \\
\text { etc.) }\end{array}$ & $\begin{array}{l}\text { Ability to frame the } \\
\text { situation for himself } \\
\text { and for others } \\
\text { ('curiosity', } \\
\text { 'autonomy', 'analytic } \\
\text { \& communications } \\
\text { skills', 'proactivity', } \\
\text { 'risk awareness', sense } \\
\text { of responsibility', etc.) }\end{array}$ \\
\hline
\end{tabular}

\section{Result $n^{\circ} 1$ : Three relationships with the organization's safety policy, stemming from one identical root}

We decided to start our analysis - and our 'results' section - by looking directly at the meaning of safety which each group constructs. At the same time, we looked at the relationship they construct with the organization's safety policy, or to phrase it differently, their perception of the organization's construction of safety. This relational aspect indeed appears as a good way to probe into each group's projected position within the organization, while simultaneously looking at its projected (appropriation) of the organization's safety culture. Our analysis confirmed the hypothesis that the meaning of safety is at least partially dependent on each group's position within the organization, which includes, on the one hand, power/hierarchical relations, and on the other hand, closeness to 'real life' safety issues.

The perception constructed by field workers of their organization's safety culture and their relationship with safety appears to be ambiguous. We named them 'distance - denunciation' and 'umbrella safety'. On the one hand, gasmen consider that they 'have the means to work safely', i.e. are provided with the equipment they need, and are not pressured to work too quickly or otherwise in a manner that they would consider unsafe. As one of the gasmen said during the interview, "I don't feel pressured. I know that if tomorrow I have an issue regarding work, they're not going to pressure me, they're not like 'you're causing us to lose money' or anything. As to equipments too, they've put down the money." On the other hand, they feel quite distant from headquarters and express that those means are mostly a way for the organization to (legally) protect itself in case anything bad happens, rather than protecting the people from possible harm. As one gasman said during an interview, 'from an equipment perspective we've got everything we need, [...] but then I 
think there are many things they do just so they're covered', which appears as quite a harsh and somewhat emotional judgment towards the organization. Gasmen refer to this supposed insincerity to account for what they perceive as an inadequate safety policy, ill-adapted to the 'real' safety issues they encounter in actual working situations. According to them, the reasons behind this inadequacy may be explained by the distance that separates fieldwork, and themselves, from those who conceive these policies, who lack understanding of real work situations, constraints and safety issues. Consistent with this perception, field workers, who have to adjust the rules to 'real' work situations, mostly see rules as obstacles in the way of 'good' work, meaning simple, smooth, efficient work.

As to frontline supervisors, they define the organization's safety policy as 'aimed at zero accidents' and consider this aim as simultaneously necessary and too ambitious This dual sense of obligation towards safety and of an impossibility to achieve it is the reason why we termed their relationship towards the organization's safety policy 'distance - responsibility denial' and their construction of the meaning of safety, 'utopia-safety'. . As an example, one frontline supervisor says, 'the organization's safety policy is zero accidents, that's for sure, zero casualties, zero accidents, zero damage on the network, but then unfortunately there are always uncertainties, an unfortunate hit with a pickaxe, it happens!' The full quote illustrates that they recognize that their organization takes measures to promote safety and provides means, i.e. personal protective equipment, rules and procedures. Yet according to them, those means are inadequate and ill-fitted to field situations, which may be explained by the fact that they are conceived at distant places that hardly maintain any relations with the field, and are therefore biased to start with. This may be illustrated by the words of another frontline supervisor, according to whom 'the policy is decided at a very high level, they do it with their own knowledge, so I'm not saying they're doing anything wrong, just that they do it with their knowledge, so us down there... life is really different, you realize that our life has nothing to do with what's on paper, so sometimes safety, well, you just have to adapt it'. Summarizing, the sentiment of this group, they perceive themselves as being confronted with a policy that is at once well-intentioned and inadequate, based on important investments but ultimately unable to fully ensure safety.

Consistent with this perception is the fact that to frontline supervisors, 'accidents are called accidents for a reason', meaning that sometimes these are unpredictable, the result of an unfortunate combination of events, and ultimately can neither be controlled nor avoided. This is the reason why we labelled this category 'utopia': their perception of safety and safety policy is rooted in the notion that even if the organization's safety policy were perfectly adequate, the very nature of accidents would render the 'zero accidents' aim unattainable. In much the same way, frontline supervisors express something close to fatalism regarding rules: it is their duty to relay rules and procedures to field workers, which requires prior understanding and some minimal degree of appropriation and endorsement. In their opinion rules are very tight as a system, but with individual rules often lacking clarity and not providing firm grounds to enforce a specific decision. Yet however inadequate the rules may be, frontline supervisors feel they have no choice but to do their best to enforce them and have field teams work as much as possible within the frame they provide.

Finally, just like the two previous groups, network supervisors acknowledge that the organization does allocate means to preserve safety, but that the safety policy is inadequate to 'real' field situations, as represented by what one of them says: 'There are the rules, and what you can do around them! Having a rule doesn't mean it is $100 \%$ applicable.' Their proactivity to ensure safety is the reason why we termed their relationship with the organization 'safety distance - reappropriation' and their construction of the meaning of safety, 'project safety'. Network supervisors 
also express a positive attitude towards safety issues and talk quite strongly about what they do to ensure safety, considered primarily as field workers' safety in emergency situations. Indeed they are the ones with the most 'rigid' discourse on safety, those who express the least ambiguity over how to manage safety issues and the least propensity to make trade-offs or negotiate over the frontiers separating safe and unsafe behaviours. The same network supervisor says, "To me it all comes down to my job, to me safety is the safety of my agents, who are under my responsibility during an intervention. To me, as network supervisor, that's safety. It may be different when you're a preparer [one of the two frontline supervisors' jobs]." All the while asserting the prime importance of safety in his own world, he therefore acknowledges that safety may have a different meaning in another social world, making explicit the notion that safety perceptions differ depending on one's job and position in the organization. Their take on the organization's safety policy and safety in general is therefore one from a distance, but a distance which they strive to bridge in their daily work. Having distanced themselves from a safety policy deemed inadequate, they build their own safety policy, a blend of field experience, company rules and sense of personal responsibility. Consistent with that, they adopt a pragmatic attitude towards rules and procedures, which need to be complied with as long as they offer the best course of action to field workers' immediate safety and the more longterm safety of the network.

Summarizing, what we see is that there is a common root to the meaning of safety as constructed by each group, namely distance. From this shared root, three different constructions stem: 'umbrella safety' for gasmen; 'utopia safety' for frontline supervisors; and 'project safety' for network supervisors. These constructed meanings are enacted throughout three types of relationship with safety and the organization's safety policy, 'denunciation', 'responsibility denial' and 'reappropriation'. These constructions seem to reflect the position of each group on the 'line' relating the organization to real life safety issues. Gasmen being the ones who are most directly exposed to harm, they construct safety issues as something one has to be protected against, which may very well account for the emotional dimension implicit in their discourse: ultimately, to gasmen, safety is perceived and constructed as their own individual, physical safety. It would therefore be fair to assume that at least part of them is afraid of harm, a fear that translates into emotionality. On their end, frontline supervisors are not directly exposed to risk, but they are responsible for the implementation of the organization's safety policy. As such they hold an intermediary position, between hierarchical responsibility and an authority which is only relative from lack of field presence, which is reflected in their ambiguous discourse over safety, constructed as simultaneously fundamentally important and partially unattainable. Finally, network supervisors are the ones whose construction of safety is the least ambiguous, which reflects their positioning as both hierarchical supervisors (when they fulfil team management duties) and technical experts and puts them in a position of holding formal and informal power.

\section{Result $n^{\circ} 2$ : The figure of the 'good gasman' illustrates how each job perceives its contribution to and relationship with safety}

Having carried out an initial analysis of the meaning of safety as constructed by the three groups, we proceeded with looking at the topic from a different angle. Indeed as was said earlier, any hazard may possibly become an accident and, at least since its creation as a full entity, the organization has been willing to make safety a full aspect of gasmen's jobs. Therefore it made sense to analyse the construction of gas-trade professionalism by our groups, and to identify the part played by safety in this construction. Here again, unsurprisingly, gasmen's professionalism is constructed differently, depending on the group. 
When gasmen are asked to describe their job and what qualities it takes to be a 'good gasman', what comes up is his ability to act within the working frame prepared beforehand by frontline supervisors, combined with the ability to manage unexpected events and situations as they arise and, in such situations, to be able to adapt the frame and fit it to the actual situation. As one of the gasmen says, "There are so many different things, connectors, materials, plugs, etc. A good gasman is the one who masters it all, all the while having the notion of gas danger in the back of his head, because it's there, but who's going to master his business, take the right initiative". One of his colleagues shares a similar insight when he states "Well, I think the company's motto has it right, 'thinking before acting', it's a good one... [...] It's true that the guy who really thinks through, who has all the ins and outs of the situation, he can make the right decision!" Access to information appears as one of the elements necessary to be a 'good gasman' and fit frames to situations. Ultimately, whether or not they are provided with the necessary information, field workers are placed in an ambiguous situation: as execution workers, they are required to submit any change of plan or decision to their supervisor, either team supervisor or network supervisor. They are therefore formally denied the discretion to act on an unapproved decision, which, should an accident occur, will protect them from being held legally accountable. But they are also the ones providing the field information on which the decision is based: they are their supervisors' 'eyes' in the field, a role on which all groups agree. As such, they play a crucial part in the decision-making process. And should the decision be retroactively considered ill-founded and trigger harmful consequences, they are likely to feel accountable for their actions, even though they may not be charged with any misdemeanour. Another possibility, should it come to that, is that they may be held accountable for not providing an accurate enough description. What is more, they are the ones on the ground facing situations ranging from construction work being delayed for technical reasons, to a gas leak in an urban environment susceptible to develop into an explosion. As such, they are directly concerned by any potential consequence of a bad decision or ill-prepared situation, including life-threatening consequences. They are therefore put in a position where they are simultaneously considered as responsible and irresponsible, which may contribute to their ambiguous position towards the organization's safety policy. Summarizing, their position seems to be built on an internal/external tension, i.e. a tension between the expectations befalling upon them from the organization and the ones issuing from real-life situations. This tension likely accounts for the ambiguity of the meaning they construct of safety, and of their relationship with the organization's safety policy. It may also account for the emotional tension of their discourse, which could result from the difficulty to process the cognitive load triggered by the management of this tension.

According to frontline supervisors, what makes a 'good gasman' are first his technical and execution skills, namely 'returning the job well-done' and knowledge of gas and associated working techniques. A good gasman is before anything 'someone who will carry out his job correctly, his onsite work without any problem [...], who's able to do a bit of everything.' It also rests on his capacity to work autonomously and responsibly within the frame that has been designed for him. In this perspective, safety appears as the ability to comply with rules, and as rules may not anticipate everything, some breaches are unavoidable. This understanding of safety and how to achieve it could be related to their own work and position in the organization. Indeed, they are in a position to influence safety by preparing work, and therefore manage and, to some extent, control it from a distance and in anticipation of working situations. Yet they are also not in a position to influence situations directly: although field workers are supposed to call them when something unexpected arises, they may not do so. And when they do the supervisor may still be unable to manage the situation for a number of reasons ranging from being unreachable when the situation arises to an inadequate description of the situation leading to a, in retrospect, bad decision. Ultimately, they feel 
that they need to do their best, but that it is not their responsibility to ensure that gasmen do not hurt themselves, as expressed by one supervisor: "In any case [safety] is their daily job, they are confronted by it on a daily basis, to them it's their life and it's perfectly normal, they have to ensure their own safety before anything else and then ensure other people's safety, [...] it really should be their priority." The ambiguity of their position therefore mirrors that of field workers, as supervisors are expected to make decisions and are generally held accountable for what happens in the field, and yet have no real control over it, as they work from a distance. Their discourse over the unavoidability of accidents seems to reflect this ambiguity: bound between an organization which they endorse and therefore cannot criticize too sharply, and a team with which they need to maintain an acceptable working relationship, considering accidents as no one's fault appears as the most reasonable option.

To finish, network supervisors' perception of a 'good gasman' is based primarily on such cognitive skills as curiosity, which allows the worker to question situations appropriately and in such a manner as to leave no grey areas, ability to act proactively and propose solutions, be comprehensive in his reports, etc. One network supervisor sums it up as follows, "A good gasman? Like I tell them, it's someone who's curious. [...] This is what makes the difference, the gas leak may smell or be visible in one place, this doesn't mean it's the end of the story, you have to check the surroundings, that's curiosity. Because you may have an expertise, but you also need to adjust to the situation, I'm not there on site, it is their duty to confirm that what l'm asking for can indeed be done, they have to assess the situation." In this perspective a good gasman is someone with whom to manage a situation that he has successfully framed, rather than someone who carries out decisions. This may be related to the fact that the network supervisors are responsible for what happens during emergency situations and, more generally, to what happens to the network, building both an individual and collective sense of responsibility. Their position within the organization is such that they have enough power and legitimacy to impose a decision, which may account for a greater sense of control over situations in general, and therefore over safety.

An aspect that seems representative of these specific constructions of gasmen professionalism is what they put behind the organization's maxim which promotes safe practices in the field, 'Thinking before acting'. Although this is aimed specifically at gasmen practices, the slogan has emerged in the interviews of all three groups, as a characteristic of 'good' gasmen and/or as representative of the organization's safety policy. Yet, the groups do not attach the same meaning to this maxim. To field workers, it designates one's ability to 'know what one is doing while doing it', referring to a combination of technical skills, experience and overall gas proficiency, which allows for and triggers self-confidence. The meaning is slightly different in the discourse of frontline supervisors, to whom 'thinking before acting' refers to gasmen's proficiency and to his self-confidence, but also to their ability to refrain from acting with overconfidence, identified as detrimental to safe work. For network supervisors the meaning switches from technical proficiency to the ability to not rush into, or out of, a situation without having made all the necessary checks and having asked all the questions to ensure the situation is fully under control. Self-confidence here is associated with the ability to remain calm and assert oneself in front of third parties pressuring to act out a certain course of action (firemen, the police and local residents) rather than to technical skills. It therefore appears that depending on the group, self-confidence is associated either with safer practices or potentially riskier practices.

To sum up, each group constructs a specific perception of gasmen professionalism and of the place occupied by safety within this professionalism. Each construction seems to reflect the group's own power over the situation: gasmen hold the ultimate, 'real-life' power, but are formally denied the 
discretion to use it; frontline supervisors hold hierarchical power, but have no real means to enforce it, other than constant availability in case something unexpected arises and a good relationship with the team of gasmen, who may behave in a more or less collaborative manner. As to network supervisors, the combination of technical expertise (i.e. informal authority) and hierarchical authority leads them constructing the most empowered discourse over safety management, but also gasmen's professionalism, which includes cognitive skills such as curiosity, analytic skills, and so on.

\section{Result $n^{\circ} 3$ : Time is of the essence, but of different essences}

The relationship between time and safety underlying the 'Thinking before acting' maxim seems to differ significantly between the groups. Indeed, the notion of time elapsed and the general feeling that time is of essence in fieldwork, especially in emergency situations, is recurrent in the gasmen's discourse, often associated explicitly or implicitly with that of 'imminent danger'. Emergency situations are ones where a gasman feels a lot of pressure to act as quickly as possible, all the while ensuring that he takes all appropriate steps to ensure his own and other people's safety. What is more, the fact that other professional groups, i.e. the police, firemen, additional technical support, etc., may also be present on site if the situation requires it, this only adds up to the pressure by multiplying the demands. Although they are not the ones who make the decisions, these are made by network supervisors, a fine line is therefore to be found between acting quickly and decisively and not rushing steps necessary to ensure safety. As expressed by one of the gasmen, "We have to act quickly when we arrive with the truck at a leak, we mustn't stall for hours, but then once it's mastered, you shouldn't rush."

Although emergency situations are the ones which best express this tension, this line needs to be walked in any situation, given that any hazard has the potential to develop into an unwanted situation and as such, seems to influence the overall perception of time by field workers. For instance, one of the reasons rules and procedures designed by the organization's safety policy are considered inadequate is because of 'the time they waste' and 'how long it would take to work if all the procedures were respected', although it has been proclaimed that there is no pressure to work at a specific pace.

At the other end of the spectrum, time management also plays an important part in managing safety for network supervisors. To them, what matters is that gasmen remain calm and take their time to go through the steps and ask themselves all the questions, however much pressure is put on them. In their discourse the overall idea seems to be that 'it is important to waste a little time to earn a lot back afterwards'. As one network supervisor says, "We manage to understand what's going on, where they are, by taking our time. We're not necessarily in a hurry, the fact that there is a gas leak that's not under control yet doesn't mean we're in a hurry, it's best to waste ten minutes now and avoid problems later on." According to them it is the only way to ensure that the situation comes back under control and back to a normal, safe status. They understand the pressure that befalls on gasmen when managing emergency situations: "It's important to make sure that we're talking about the same thing so you have to take your time, which when you're on the field may feel like a really long time. A quarter of an hour when you're in the field close to a gas leak feels like a really long time." They consider it part of their duty to help gasmen keep their calm, lower the pressure and if necessary, remind them of the questions and checks to be carried out. Although they express an understanding of the way field workers experience time, the experience of network supervisors appears as radically different, therefore contributing to building a relationship to real work and safety which is likely to differ. 
Finally, frontline supervisors seem to hold an intermediary position, which may be accounted for, on the one hand, by the necessity to factor in human resources aspects such as the time spent by a worker on a specific project and cost-effectiveness, team management aspects, etc. and on the other hand by their lesser involvement in emergency-related situations. Their take on time is mostly that work has to be time-efficient, meaning that a gasman should take his time to work properly, paying attention to his environment and to what he is doing so as to make no mistake, and working as quickly and efficiently as possible within this frame. The way time is experienced by frontline supervisors appears to be less sensitive than for the other two groups, which shows in the relative absence of the theme in their discourse.

As a conclusion, it seems fair to infer from these specific experiences of time, and specific construction of time as a safety risk, that each group experiences a specific relationship to safety management in real-life situations. This in turn is likely to trigger specific enactments of safety and ultimately impact an organizational safety culture.

\section{Discussion of results}

When comparing the groups it seems that they all share a relationship with the organizational, projected safety culture, rather than share a safety culture themselves. This relationship is based on two main components, one of which is the recognition of corporate investment and objectives in favour of safety, and the other one, the basic assumption that safety rules are inappropriate and a subsequent dissociation from those rules and objectives. All groups diverge in the reasons laying behind that dissociation and the specific representations of safety each group builds. It is the mechanisms working behind these specific constructions which we are now going to discuss.

\section{Ambiguous safety policy to manage uncertain situations}

According to Weick, 'Although the word ambiguity also means the presence of two or more interpretations, it can also mean something quite different, namely a lack of clarity, which [...] makes it quite similar to uncertainty. [...] Ambiguity understood as confusion created by multiple meanings calls for social construction and invention. Ambiguity understood as ignorance created by insufficient information calls for more careful scanning and discovery' (Weick, 1995, p.95).

Following Weick's reasoning, we can say that all three groups perceive the organization's safety policy as ambiguous in the first sense, as it has reached a point where it no longer makes sense in actual situations, where it does not provide clear guidance as to how to ensure safety in real work situations. This first ambiguity is complemented with the second one that is to be found in real work situations, which will be termed uncertainty. Therefore, the organization's safety policy also fails to reduce uncertainty giving the additional clarification work necessary to ensure compliance. In this perspective, the cognitive load required to enact the organization's safety policy is such that it becomes easier for people to build their own frames of reference and therefore their local safety cultures, rather than work within the organization's.

Paradoxically, the organization is tightly coupled, and an important benefit of tight coupling is to reduce ambiguity. It might be that the coupling has become so tight that it has moved beyond the point where it can serve as cognitive framework and point of reference reducing ambiguity in situations, and reached a point where it does not leave any space for situations to be fit in and made sense of. If what the organization offers cannot be made sense of, people end up developing alternatives and create their own cognitive frameworks. Yet each group manages ambiguity (of the safety policy) and uncertainty (of real work situations) in its own way, depending on both its position within the organization and relationship to field work. 
Field workers are most directly confronted with ambiguous situations. As appears in their discourse, ambiguity results from the fact that any work situation at one point includes unforeseen elements, hence becoming uncertain. They consider themselves not being in a position to manage such situations for lack of information, missing either elements of context (so-called 'ins and outs of the situation') or clear rules that they could apply. Therefore they have the choice to either face uncertain situations by playing an active part in developing and implementing a solution, or to retreat, in which case they leave it to a supervisor to make a decision. The possibility to act or to retreat is reflected in what a 'good gasman' is to gasmen themselves, namely someone who is able to adapt and fit the official frame to actual situations. The alternative option always remains open, and is in many ways the safest option, as it allows to remain under the organization's 'umbrella' in case something bad happens. In this perspective a 'good gasman' is someone who, when facing an ambiguous situation, has enough skill, experience and confidence to make a decision on his own and stand by it. In the gasmen's discourse the uncertainty of real work situations and subsequent need for clear directions is stated as a matter-of-fact, and leads to the criticism of what is considered as the unwillingness, or inability of the organization to take a clear stand and reduce ambiguity.

Ambiguity is not as present in the discourse of frontline supervisors. To them the inadequacy of the organization's safety policy is mostly a matter of distance and misunderstanding. As a consequence they regret such ambiguity, but explain it almost as if it were an honest mistake; the result of an inevitable situation inherent to a large and somewhat disorganized organization, rather than an intended attempt to maintain grey areas. As to real work situations, frontline supervisors see them as mostly uncertain and unpredictable, i.e. requiring in situ fitting, which could be avoided if work would be prepared differently, rather than ambiguously, i.e. requiring to make a call without having all the necessary information. This may be accounted for by the fact that they are hardly ever confronted with actual field situations and decisions.

Ambiguity is almost absent from network supervisors' discourse, where uncertainty and the importance of questioning and going to the bottom of situations to ensure no grey area remains, appear as crucial. Uncertainty, including the one caused by an inadequacy of safety policy, is considered through a pragmatic lens, not for itself but as a situation to be managed. It is addressed through the means to reduce and even eliminate it, namely by thoroughly questioning workers/situations/the environment, going to the bottom of things ('not leaving a stone unturned') and remaining fixed on the all-important aim of ensuring safety of workers and network resilience.

To sum up, the inadequacy of the organization's safety policy is considered to be ambiguous to varying degrees, depending on the group's relationship to fieldwork and to safety issues, and each group seems to have designed its specific way to manage both the ambiguity of safety policy and the uncertainty inherent to real work situations.

\section{A hiatus in the rules enactment process and culture development cycle?}

Another reason that may account for the differences between the way the organization's safety policy is perceived, is what can be considered as a hiatus in the enactment process of rules and procedures. Indeed, each group entertains a specific relationship to rules and procedures, which depends on both its position within the organization and its proximity to 'real' work. Field workers fit rules to situations and therefore play the 'acting' part of the process. Frontline supervisors interpret and relay the rules, which may be considered as a translation and general compliance function which helps build the company's compliance framework. As to network supervisors, they adapt rules to their specific aims, namely ensuring (short-term) safety of the workers and the environment and network resilience and therefore build a situational, or field-rooted compliance framework. 
As those two groups occupy different positions within the organization and have different objectives - human resources management and planned on-site work preparation for frontline supervisors, network durability for network supervisors - a gap is likely to exist from the start between the general and situational frameworks. This is further reinforced by the fact that the groups hardly ever work together and therefore have little opportunity to confront and, if relevant, readjust their frameworks. Real work situations are therefore the only ones where official and field-rooted frames are confronted, which, should it come to that, leaves it to the responsibility of gasmen to make choices. Gasmen who are not empowered to make such decisions, and who in any case have not contributed to the development of the official framework and therefore are not aware of its original shape, rendering them unable to effectively make adjustments.

Returning to Weick, he writes 'I use the word enactment to preserve the fact that, in organizational life, people often produce part of the environment they face (Pondy \& Mitroff, 1979).' (Weick, 1995, p.30) and insists on the authoritative quality of enactment. In this perspective, frontline supervisors do not receive feedback ('stimuli') on the general compliance system they build. Network supervisors receive feedback, but only know of part of its source, as they are not familiar with the framework built by frontline supervisors, in which field workers are supposedly operating. As to field workers, they are confronted with two distinct, and potentially contradictory frameworks that are equally legitimate, which under extreme circumstances may bring them close to a situation of paradoxical injunction (Bateson et al., 1956). Ultimately, it therefore seems that the current repartition of roles and responsibilities between the three groups does not allow for proper enactment of safety rules and procedures, hence at least partially accounting for the heterogeneity of the organization's 'safety culture'.

Returning to Berger and Luckmann's model of culture development, the actual process taking place within the organization is depicted in Figure 2.

Figure 2 - Adapted representation of Berger and Luckmann's model of culture development applied to the organization studied

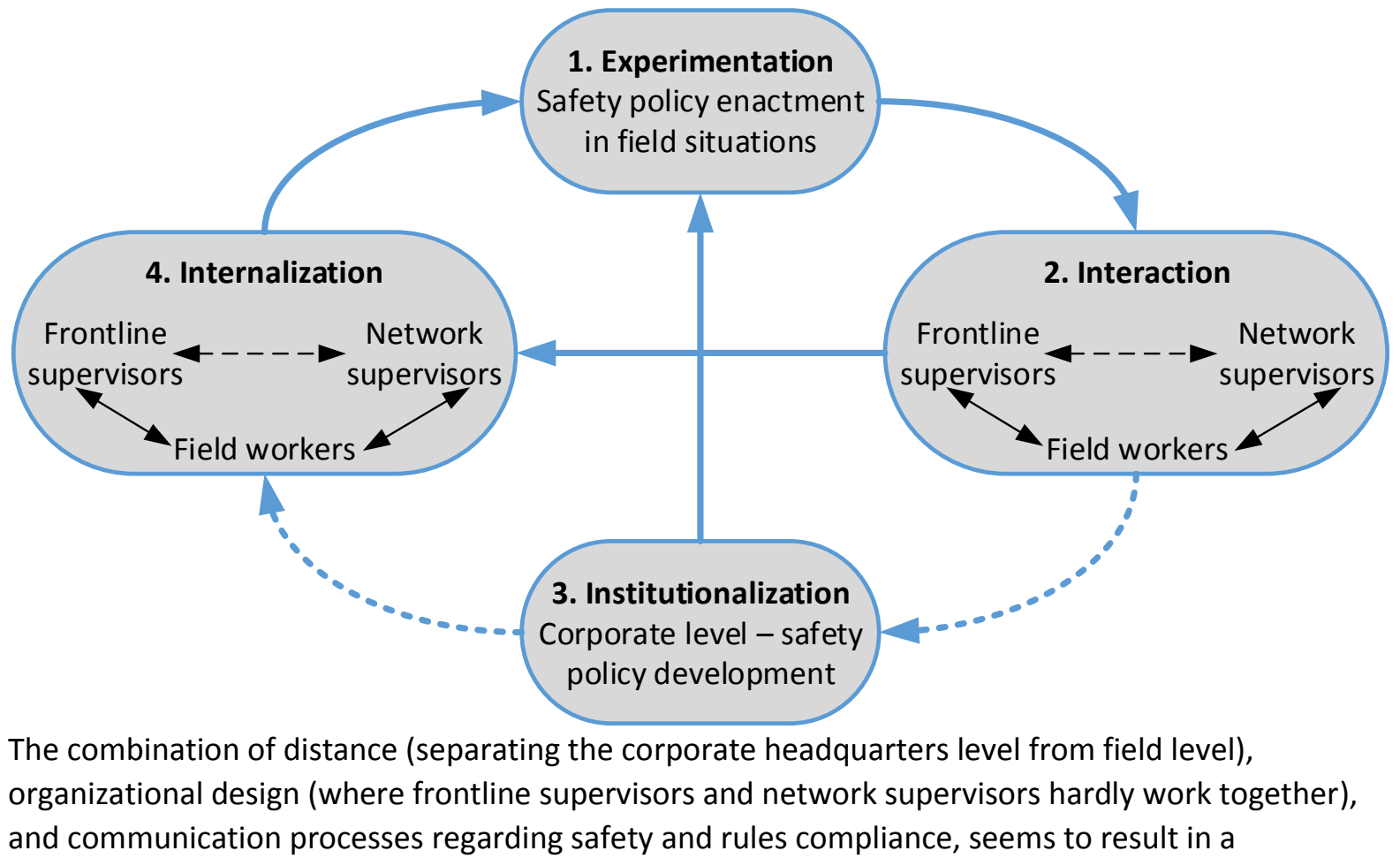


development cycle that is broken down into two sections (represented in the model by dotted arrows).

Firstly, the 'Institutionalization' phase of the cycle appears to be disconnected from the previous 'Interaction' and subsequent 'Internalization' phase. Indeed, as in most big organizations, the material and symbolic distance between field level and local and national headquarters is such that it prevents a completely successful appropriation by the organization of the standard behaviours and understandings which have been developed at field level, which consequently have difficulty being institutionalized. The gap separating corporate rules and policy from what is practised and expressed at the sharp end of operations illustrates the lack of 'shared perceptions of daily practices [which] should be considered to be the core of an organizational culture' (Hofstede, 1997). As a consequence, institutionalized safety rules and policy are perceived as not reflecting field concerns and practices. They are therefore received with suspicion or even outright rejection and are not internalized by the group as 'the way to do things around here.' This is reinforced by the fact that those who actually enact these rules and policies in the field receive them through their managers, who in addition may not have appropriated these rules perfectly and/or may not fully agree with their content, as has been illustrated by the discourse constructed by the group of frontline supervisors. This disconnection separates corporate headquarters from all field situations and thus from our three categories of employees, hence accounting for the distance experienced and expressed by them all.

Secondly, within the 'Interaction' and 'Internalization' phases, the absence of substantial relationships between frontline and network supervisors prevents the development of standard behaviours and understandings common to all three groups and therefore tends to reinforce the strength and specificity of each group's safety discourse.

\section{Conclusion}

The social constructionist perspective has provided a heuristic to analyse the material gathered in the field and helped shed light on what initially appeared as a paradoxical situation. Indeed it has helped explain the reasons why despite a broadly shared recognition of the organization's investment in favour of safety, significant resistance and distance towards its safety initiatives could be identified.

A discourse analysis of interviews carried out with three groups of employees (field workers, frontline supervisors and network supervisors) resulted in the identification of a 'root' perception of, and relationship with, the organization's safety policy, common to all three groups. This perception is distance, and the subsequent conviction that truly safe and relevant working practices are to be developed (constructed) in the field rather than by corporate rules. The notion that 'true' safety is to be developed in the field rather than at corporate level comes up in comparable studies and does not as such constitute a result; but understanding the organizational processes which allow for such a belief - in our case, the broken down rules enactment/culture development cycle - appears as a promising result which could be expanded further with a more extensive sample.

Additionally, the study has shown that from this common 'distance' root, three distinct safety discourses grow, and that each discourse may be correlated to each group's work and position within the organization. This underlines the relevance of the social constructionist perspective on organizational and safety culture and the fact that with each social world comes a specific way to speak about and represent reality as it is perceived. Considering the limited size of the sample, it would seem relevant to test this initial result on a broader scale, paying particular attention to the 
composition of each group and the impact of this composition on the strength of its discourse. Indeed, the homogeneity of the groups interviewed in this study appeared simultaneously as an advantage, as it helped notions and themes emerge clearly, and as a disadvantage, as the discourse identified may be dependent on the specific history and experience of the group's members, as much as on their position within the organization. In particular, further research could therefore look into a discourse's homogeneity beyond geographical and experiential diversity.

Finally, although the current size of our sample cannot provide the full spectrum of discourses on safety within the organization, it provides us with insight into safety discourses currently active within the organization and, maybe more importantly, into the mechanisms underlying their development. We believe it contributes to documenting research on organizational culture development and more specifically, on the way a safety culture is articulated within its broader working and organizational context, which it both results from and constructs. It therefore provides sufficient ground for further research based on either a larger or a quite different sample in order to broaden and expand our results.

\section{References}

Bateson, G., Jackson, D. D., Haley, J. \& Weakland, J., 1956. Towards a theory of schizophrenia. Behavioral Science 1 (4), pp. 251-264.

Berger, P.L. and Luckmann, T., 1966. The social construction of reality. Penguin Books, New York Burr, V., 2003. Social constructionism ( $2^{\text {nd }}$ revised edition). Routledge, London.

Desmorat, G., Guarnieri, F., Besnard, D., Desideri, P., Loth, F., 2013. Pouring CREAM into natural gas. The Introduction of Common Performance conditions into the safety management of gas networks. Safety Science 54, pp.1-7.

Guldenmund, F. W., 2010. Understanding and exploring safety culture. BOXPress, Oisterwijk (NL).

Guldenmund, F.W., 2014. Organisational safety culture principles. In: Waterson, P. Patient safety culture: Theory, methods and application. Ashgate, Farnham (UK).

Hofstede, G., 1997. Cultures and organizations. McGraw-Hill, New-York.

Hopf, C., 2004. Qualitative interviews: An overview. In U. Flick, E. v. Kardoff \& I. Steinke (Eds.). A companion to qualitative research, pp. 203-208. Sage Publications Ltd, London.

Hopkins A., 2006. Studying organizational cultures and their effects on safety. Safety Science 44 (10), pp. 875-889.

Kowal, S. and O'Connell D.C., 2004. The Transcription of conversations. In U. Flick, E. v. Kardoff \& I. Steinke (Eds.). A companion to qualitative research, pp.248-252. Sage Publications Ltd, London.

Martin, J., 2002. Organizational culture: mapping the terrain. Sage Publications, Thousand Oaks (USA).

Jorgensen, M. and Philips, L., 2002. Discourse analysis as theory and method. Sage Publications Ltd, London.

Paillé, P. and Mucchielli, A., 2005. L'Analyse qualitative en sciences humaines et sociales. Armand Collin, Paris. 
Schein, E.H., 2004. Organizational culture and leadership (3rd edition). Jossey Bass, San Francisco.

Spencer-Oatey, H. (Ed.), 2000. Culturally speaking: Managing rapport through talk across cultures. Continuum, London.

Terssac (de), G. (Ed.), 2003. La Théorie de la régulation sociale de Jean-Daniel Reynaud. La Découverte, Paris.

Weick, K. E., 1995. Sensemaking in organizations. Sage Publications, Thousand Oaks (USA).

Weick, K. E., 2001. Making sense of the organization. Blackwell, London.

Wetherell, M., 1998. Positioning and interpretive repertoires: conversation analysis and poststructuralism in dialogue. Discourse and Society 9 (3), pp.387-412. 